serious gastric disturbances were also remedied by the same means the author thinks that they were often due to the absence of sufficient free acid in the gastric juice.

Gastro-intestinal catarrh, which is often so dangerous an affection in infants, was treated with gum arabic, one to two teaspoonfuls in half a pint of the preparation of condensed milk previously described. This was given immediately after the first symptoms of an attack, and was repeated with each portion of milk. In some instances the next discharge was rendered normal. The good effect was considered to be owing to the emollient action of the gum arabic upon the mucous membrane of the stomach and bowels, as well as to the mechanical covering supplied to the lining coat. It was also supposed to assist in dissolving the caseons coagula.

A daily bath of two or three minutes was given to all the children, the temperature of the water being at $26^{\circ} \mathrm{R} .\left(90.5^{\circ} \mathrm{F}\right.$.). The thermometer in the rectum showed that the temperature of the body was not affected thereby. This agrees with the experiments of Liebermeister, Kernig, Jürgensen, and others as to the effect of cool baths of moderate duration on healthy persons. The variation in temperature was never more than one tenth of a degree Centigrade.

\title{
THE BOSTON SOCIETY OF MEDICAL SCIENCES.
}

\section{EXTRACTS FROM REPORT OF PROCEEDINGS FOR OCTOBER AND NOVEM- BER, 1876.}

JAMES J. PUTNAM, M. D., SECRETARY.

Tuesday, October 30th. Pain in Facial Paralysis. - Dr. Webber read a paper illustrated by diagrams upon the significance of pain as a concomitant symptom of facial paralysis. After referring to the fact that so little is to be found on this subject in the text-books, he said that in more than half the cases of facial paralysis which he had observed, pain had been present, though its exact seat had been noted in five cases only. In those the pain had been chiefly in and behind the ear and along the lower jaw ; in one or two cases its distribution had been more general. He regarded it as possible that branches of the fifth pair might be affected in their bony canals, like those of the seventh, so as to cause pain and numbness, but, finding that the facial nerve is known to anastomose with the auricular branch of the pneumogastric, which traverses a canal in the mastoid bones, the idea had suggested itself that the same infuence which causes the facial paralysis might implicate this auricular branch. This might happen even before the facial nerve was attacked, causing the pain to precede the loss of motion, or the two affections might even take place simultaneously. The auricular branch is distributed to the parts where the pain was felt in the cases reported, though in some of them there had also been pain in parts supplied by the fifth nerve.

In reply to Dr. Dwight, Dr. Webber said he believed the anastomosis referred to to be a constant one. 
In answer to Dr. Fitz he said that there was no reason to regard this paralysis of the facial as rheumatic in the strict sense of the word, but that in many cases, at least, it was reasonable to suspect the presence of an inflammation of the nerve sheath, causing pressure on the nerve fibres, though no proof could be given of the fact.

Dr. Putnam had seen a number of cases in which pain associated with tenderness on pressure had been present in various parts of the face, but especially along the side of the forehead at certain points; and he had believed these symptoms to be due to an inflammation of the sheaths of the terminal fibres of the facial nerve involving fibres of the fifth nerve, possibly those, if such exist, which ramify in the sheaths of the motor nerves. He had also recently seen a case belonging to the type of the moderately severe cases of facial paralysis, of so-called rheumatic origin, where the patient when asked to point out the parts where the pain was the severest touched in turn almost exactly the places at which the main branches of the fifth nerve leave their bony canals.

Distribution of the Median and Ulnar Nerves. - Dr. Putnam showed two colored casts illustrating the position of the anæsthetic zone in a case of accidental section of the median and ulnar nerves at the wrist. The case had repeatedly been examined with care and the limits of the anæsthesia as mapped out corresponded to the condition of the patient several months after the accident. The sensibility of the entire palm was more or less impaired, though but very slightly so over an area bounded anteriorly by a line which corresponded almost precisely with the superficial palmar arch. This area must therefore have received its sensitive nerve supply either from cutaneous nerves given off from the brachial plexus or from branches of the median and ulnar given off above the seat of injury (palmaris ulnaris and medius). Beyond the line indicated the skin became rapidly insensible to the strongest excitations of every kind, the intervening zone, where touch alone was abolished, having a width of not more than one third of an inch. All the palmar surfaces, strictly speaking, of the fingers and the thumb were completely anæsthetic, except that the first phalanx of the little finger was partially sensitive, being apparently supplied in part by a branch of the dorsal division of the ulnar, which for other reasons was believed to have escaped section, namely, because the sensibility over the back and sides of the little finger was unimpaired. The radial nerve was found to supply the entire backs of the thumb and of the first two phalanxes of the index finger and the first phalanx of the two middle fingers.

The distribution of the median and ulnar to the fingers as thus ascertained was shown to agree strikingly with that laid down by Richelot as a result of his careful dissections. The fact that the limits of the anæsthesia in this and in certain other cases referred to were so exactly defined could not but suggest a doubt as to whether the observations of Arloing and Tripier upon animals, which showed such an extensive overlapping of the areas of distribution of the different nerve territories, due to recurrent nerve fibres, are to be regarded as applicable with propriety to man.

Dr. WEBBER referred to the great variations between different cases, as to the distribution of the median and ulnar nerves. 